\title{
Selection of native Tunisian microalgae for simultaneous wastewater treatment and biofuel production
}

\author{
A. Jebali ${ }^{1,2}$, F.G. Acién ${ }^{2,3}$, C. Gómez ${ }^{2,3}$, J.M. Fernández-Sevilla ${ }^{2,3}$, N. Mhiri ${ }^{1}$, F. \\ Karray $^{1}$, A. Dhouib ${ }^{1}$, E. Molina-Grima ${ }^{2 *}$, S. Sayadi ${ }^{1}$
}

${ }^{1}$ Laboratory of Environmental Bioprocesses, Sfax Centre of Biotechnology, University of Sfax, BP 1177, 3018 Sfax, Tunisia

${ }^{2}$ Chemical Engineering Department, University of Almería, 04120 Almería, Spain. ${ }^{3}$ CIESOL, Joint center University of Almeria-CIEMAT, 04120 Almería, Spain

*Author for correspondence: Emilio Molina Grima

Chemical Engineering Department, University of Almería

Carretera Sacramento s/n, E04120, Almería, Spain

Telephone: +34 950015032; Fax: +34 950015484; e-mail: emolina@ual.es 


\begin{abstract}
This paper focuses on the selection of native microalgae strains suitable for wastewater treatment and biofuel production. Four Chlorophyceae strains were isolated from Northeastern Tunisia. Their performances were compared in continuous mode at a 0.31 day dilution rate. The biomass productivity and nutrient removal capacity of each microalgae strain were studied. The most efficient strain was identified as Scenedesmus sp. and experiments at different dilution rates from 0.2 to 0.81 /day were carried out. Maximal biomass productivity of $0.92 \mathrm{~g} / \mathrm{L} \cdot$ day was obtained at $0.61 /$ day. The removal of chemical oxygen demand (COD), ammonium and phosphorus was in the range of 92$94 \%, 61-99 \%$ and $93-99 \%$, respectively. Carbohydrates were the major biomass fraction followed by lipids and then proteins. The saponifiable fatty acid content was in the 4.9$13.2 \%$ dry biomass range, with more than $50 \%$ of total fatty acids being composed of saturated and monosaturated fatty acids.
\end{abstract}

KEYWORDS: microalgae, wastewater, biofuel, productivity, biochemical composition 


\section{Introduction}

Over the last century, increasing energy demand has led to the intensive use of fossil fuels like coal, petroleum and natural gas. The depletion of these conventional fuels and their environmental impact, in terms of global warming, has prompted scientists to explore sustainable alternative biofuel resources. Recent research initiatives have established that microalgal biomass appears to be a potential candidate as a renewable fuel resource (Chisti, 2007). In fact, microalgal biomass possesses several desirable characteristics for use as an alternative fuel feedstock when compared to others (lignocellulosic biomass, crops and animal fat etc.) such as a rapid growth rate, high lipid content and the ability to grow on non-arable land while using various water sources, e.g. wastewater (Brennan and Owende, 2010). Water is a precious resource that must be judiciously used and the application of non-potable water for microalgae cultivation could minimize water utilization. In fact, most of the freshwater consumed is disposed of after use into aquatic environments in the form of wastewater, which is rich in nutrients, posing a serious eutrophication risk. On the other hand, commercial microalgae production faces an economic feasibility issue because of the high operating costs, which include culture medium costs (Acién et al., 2011, Acién et al., 2012) in light of its low productivity - all of which reduces the attractiveness of microalgae as a sustainable alternative (Abou-Shanab et al., 2013, Chen et al., 2015). Therefore, combining both wastewater treatment and algal biomass production appears to be a viable solution in ensuring economic and environmental benefits from the development of microalgae-based fuel and products.

Numerous studies have pointed out the efficiency of microalgae in removing nutrients from different types of wastewater as well as in achieving high productivities. Selecting appropriate strains that have good wastewater tolerance is an essential criterion in 
achieving the maximum benefit from the microalgae. In fact, naturally-adapted microalgae that are isolated from wastewater treatment plants, or natural water bodies, usually exhibit better growth and adaptation to culture conditions in wastewater and to efficient bioremediation (Osundeko et al., 2013). Previous works have demonstrated significant nitrogen and phosphorus removal using secondary effluent (McGinn et al., 2012; De Alva et al., 2013), primary wastewater (Osundeko et al., 2013; Cho et al., 2013), piggery wastewater (Abou-Shanab et al., 2013), or even raw centrate ( $\mathrm{Li}$ et al., 2011). However, few of the studies reported biomass productivity information obtained in continuous mode using non-sterilized wastewater (Gómez et al. 2013, Li et al., 2011).

The objective of this work was to investigate the suitability of native strains from North-eastern Tunisia for use in the wastewater treatment process and in biodiesel production. For this, different strains were isolated from extreme environments; experiments in continuous mode were performed to evaluate the behavior of each and to identify the most promising strain in terms of biomass production and nutrient removal capacity. Afterwards, the leading strain was studied in more detail by analyzing the influence of dilution rates on the productivity and the biochemical composition of the biomass. Nutrient removal, biomass productivity, photosynthetic activity and biochemical composition, including the saponifiable fatty acid content and profile, were evaluated. This information allows the selection of the most suitable strain to use at the pilot scale as a prior step to industrial development. 


\section{Materials and methods}

\subsection{Microalgae isolation and identification}

Four different strains were isolated from North-eastern Tunisia. Strain WT6 was isolated from a thermal freshwater source whereas the three other species (Strain WT8, Strain WT9 and Strain WT10) were isolated from a Tunisian wastewater treatment plant. To isolate each strain, $10 \mathrm{~mL}$ of water sample were filtrated through $0.7 \mu \mathrm{m}$ filters, inoculated into $100 \mathrm{~mL}$ MDM medium (Ichimura and Itoh, 1977) in a $250 \mathrm{~mL}$ conical flask and then incubated (without agitation) at $25 \pm 3^{\circ} \mathrm{C}$ and at $80 \mu \mathrm{mol} \cdot \mathrm{m}^{-2} \cdot \mathrm{s}^{-1}$ under continuous illumination for 30 days. The microalgae were later subjected to purification by successive serial dilutions followed by the streak-plate method. The process was repeated until a bacteria-free and fungi-free algal colony was obtained. Microscopic observations were performed to check the purity of a single algal clone. The individual colonies were inoculated into MDM medium plates and kept as pure cultures. Additionally, pure clones were inoculated into liquid MDM medium, and incubated at $25 \pm 3^{\circ} \mathrm{C}$ under continuous illumination. Strain identification was carried out through microscopic observations and molecular methods using 18S rRNA sequence analysis.

\subsection{DNA extraction, PCR amplification of $18 \mathrm{~S}$ rRNA and sequencing}

The genomic DNA from the different strains was extracted using the FavorPrep Plant genomic DNA extraction mini kit according to the manufacturer's instructions. The sequence for the $18 \mathrm{~S}$ rRNA gene ( $S S U$ rRNA) was obtained by PCR amplification. PCR reaction was performed in a $50 \mu \mathrm{L}$ reaction volume containing $0.2 \mathrm{mM}$ each $\mathrm{dNTP}, 0.2$ $\mu \mathrm{M}$ of each primer, $50 \mathrm{ng}$ DNA template and 2.5 U of TOP-Taq DNA polymerase (BIORON) in the reaction buffer supplied by the manufacturer. PCR programme was as follows: denaturation by heating for $3 \mathrm{~min}$ at $94{ }^{\circ} \mathrm{C}$, followed by 30 cycles of $45 \mathrm{~s}$ at 
$94^{\circ} \mathrm{C}, 1 \mathrm{~min}$ at $58^{\circ} \mathrm{C}$ and $3 \mathrm{~min}$ at $72{ }^{\circ} \mathrm{C}$, then a final elongation step for $5 \mathrm{~min}$ at $72{ }^{\circ} \mathrm{C}$. The PCR products were purified and sequenced using the Sanger methodology. The target sequences were analyzed using BLAST online (http://www.NCBI.nim.nih.gov/). Multiple alignments were generated with the MUSCLE program (http://www.ebi.ac.uk/Tools/msa/muscle/). The sequenced regions of 18S rRNA gene were submitted to GenBank database and registered under the accession numbers KT267272, KT285521 and KT285522 for Strain WT6, Strain WT8 and Strain WT9, respectively.

\subsection{Experimental culture conditions}

Experiments were run in triplicate using 12 glass bubble column reactors with spherical bases (diameter: $3 \mathrm{~cm}$; height: $45 \mathrm{~cm}$; working volume: $250 \mathrm{~mL}$ ). The cultures were continuously aerated at a flow rate of $0.3 \mathrm{v} / \mathrm{v} / \mathrm{min}$. The $\mathrm{pH}$ was maintained within the optimum range, 7.8-8.0, by on-demand $\mathrm{CO}_{2}$ injection at a flow rate of $0.01 \mathrm{v} / \mathrm{v} / \mathrm{min}$. The temperature was kept constant at $25^{\circ} \mathrm{C}$ by controlling the room temperature. A set of 8 $28 \mathrm{~W}$ daylight fluorescent tubes (Philips Daylight T5), located horizontally $1 \mathrm{~cm}$ apart and $4 \mathrm{~cm}$ from the cultures, was used to artificially illuminate the vessels and simulate the circadian cycle. The maximum irradiance was $800 \mu \mathrm{E} \mathrm{m}^{-2} \mathrm{~s}^{-1}$, measured with a spherical quantum sensor, SQS-100 Walz GmbH (Effeltrich, Germany). Wastewater from a wastewater treatment plant in Almería (Spain) was used as the culture medium. The wastewater was taken directly from the industrial plant and used as the culture medium. It was only filtered through a $100 \mu \mathrm{m}$ filter to remove solids. No sterilization was performed. Two different wastewater batches were used and their composition is shown in Table 1.

To evaluate the different isolated strains, experiments were conducted simultaneously, with the four strains in parallel, starting with an equal cell density, of $1.210^{7}$ cell $/ \mathrm{mL}$, 
while operating in batch mode for 6 days; after which the cultures were operated in semi-continuous mode at $0.31 /$ day. Semi-continuous operation was maintained until steady state was achieved (washing the reactor volume three times) - data from the last three days were used. To evaluate the performance of the leading strain, the same methodology was employed but experiments were performed at different dilution rates, from 0.2 to 0.81 day in triplicate.

\subsection{Determination of biomass concentration and fluorescence measurements}

Aliquots of culture were sampled daily to measure microalgae biomass by optical density at $750 \mathrm{~nm}$ (OD750) using a spectrophotometer (Thermo Scientific Genesys 10S UV-Vis). The dry weight biomass concentration was determined by filtrating $100 \mathrm{~mL}$ of culture through a pre-dried $1 \mu \mathrm{m}$ filter (Macherey-Nagel GmbH \&Co.KG, Germany) and drying it in an oven at $80{ }^{\circ} \mathrm{C}$ for $24 \mathrm{~h}$. A calibration curve was obtained to convert the OD750 values to biomass dry weight. The $\mathrm{pH}$ in the vessels was also measured by a separate probe to ensure it was not drifting. In addition, chlorophyll fluorescence, as Fv/Fm, was measured daily using a fluorometer (AquaPen AP 100, Photon Systems Instruments, Drasov, The Czech Republic) in order to check the cells' physiological status. All the analyses were carried out in triplicate and the mean value was reported.

\subsection{Analytical procedure}

At steady state, biomass was harvested by centrifugation at $7500 \mathrm{rpm}$ for $5 \mathrm{~min}$ (SIGMA 4-15 Sartorius, Goettingen, Germany), washed twice with distilled water, freeze dried and used to determine the biochemical composition. Protein content was quantified according to the modified Lowry method proposed by Herbert et al. (1971). Total lipids were determined as described by Kochert (1978). The fatty acids content and profile were obtained by direct transesterification and gas chromatography (Agilent 
Technologies 6890 N Series Gas Chromatograph, Santa Clara, CA, USA) as described by Rodríguez-Ruiz et al. (1998). Ash was determined by incinerating a $100 \mathrm{mg}$ sample in an oven at $450{ }^{\circ} \mathrm{C}$ for $48 \mathrm{~h}$. The carbohydrate content was estimated by subtracting the sum of the other fraction percentages (ash, lipids and proteins) from 100.

Regarding the nutrient removal efficiency, $50 \mathrm{~mL}$ of sample was collected from each experiment at steady state and filtrated using $1 \mu \mathrm{m}$ filters (Macherey-Nagel GmbH \&Co.KG, Germany); the filtrate was used for nutrient analysis. Chemical Oxygen Demand (COD) was determined using Hach Lange kits (LCI 400). The analyses of nitrate, ammonium and phosphate were performed by colorimetric methods. The phosphate was measured by visible spectrophotometry through the phospho-vanadomolybdate complex (Phosphate Standard for IC: 38364$)$. The nitrate was quantified by measuring optical density at $220 \mathrm{~nm}$ and $275 \mathrm{~nm}$ (Nitrate Standard for IC: 74246). The ammonium was measured according to the Nessler method (Ammonium standard for IC: 59755).

\section{Results and Discussion}

\subsection{Identification of microalgal strains through $18 \mathrm{~S}$ rRA sequence analysis}

Three microalgae strains were isolated from a wastewater plant at different stages of treatment and another was isolated from a thermal water station in Tunisia. Microscopic observations indicated that these microalgae species belong to the Chlorophyta division (Figure 1). The sequences encoding the 18S rRNA genes were obtained as described in Materials and methods, analysed and compared with sequences already available in Genbank database. Strain WT6 was identified as Scenedesmus sp., as its 18S rRNA sequence showed $\geq 99.9 \%$ similarity with Scenedesmus species such as Scenedesmus (Acutodesmus) rubescens CCAP 232/1 (Kessler et al., 1997), S. dissociatus UTEX 1537 (Hegewald and Hanagata 2000), S. littoralis (Hanagata, 2001), S. distendus Hegewald 
1975-267 (Hegewald and Hanagata 2000) and S. deserticola BCP-EM2-VF3 (Lewis and Flechtner, 2004). Similar analysis allowed identification of strain WT8 as Chlorella vulgaris, and strain WT9 as Chlorella sp. Morphologically, strain WT10 was identified as Scenedesmus sp.

\subsection{Performance of isolated strains}

The performance of the isolated strains was studied to determine their robustness and growth yield in wastewater as culture medium. The composition of the wastewater used is presented in Table 1 . The COD concentration comprised 1,120-1,180 mg/L. The nitrogen and phosphorus contents were in the $61.7-63.5$ and $6.5-21.9 \mathrm{mg} / \mathrm{L}$ range, respectively. According to Rawat and co-workers (2011), this wastewater is considered highly concentrated and nutrients concentrations are higher than the values reported in wastewater used by other authors (Abou-Shanab et al., 2013, Feng et al., 2011, De Alva et al., 2013). In treatment facilities wastewater is naturally colonized by species such as Chlorella sp., Scenedesmus sp. or microalgae belonging to the Bacillariophyta and Cyanobacteria groups (Miksch et al., 2015). Furthermore, wastewater is a source of valuable nutrients for microalgae growth but it also contains toxins, predators and competing microorganisms that might have an inhibitory effect on the microalgae (Cho et al., 2013). The selection of the appropriate strain for the removal of nutrients from a wide variety of wastewaters is a crucial step in the research investigating economicallyviable microalgae production and applications. Chlorella sp. and Scenedesmus sp. have been commonly used for wastewater treatment and previous studies have revealed their nutrient take-up efficiency (Li et al., 2011, De Alva et al., 2013, Arbib et al., 2014).

All the isolated strains grew in wastewater, which implies that this medium can support microalgae growth requirements and that the strains fully adapted to it. Figure $2 \mathrm{~A}$ 
depicts the biomass productivity variation for the different strains at steady state. The biomass productivities obtained were $0.6,0.5,0.6$ and $0.6 \mathrm{~g} / \mathrm{L} \cdot$ day for strain WT6, strain WT8, strain WT9, and strain WT10, respectively. These results do not show significant differences between any of the strains since the environmental conditions tested were the same. The results obtained are in the range of values reported in the literature. In fact, McGinn et al. (2012) reported a Scenedesmus sp. AMDD biomass productivity of $0.27 \mathrm{~g} / \mathrm{L} \cdot$ day at a dilution rate of $0.751 /$ day using ultrafiltrated secondary municipal wastewater effluent, whereas Li et al. (2011) reported a productivity of $0.92 \mathrm{~g} / \mathrm{L}$.day by growing Chlorella sp. on raw centrate at $0.51 /$ day. The productivity values are comparable to those reported by Gómez et al. (2013), who obtained a productivity of $0.5 \mathrm{~g} /$ L.day from Muriellopsis $\mathrm{sp}$. using secondary treated wastewater as the culture medium at a dilution rate of 0.31 day. The physiological cell status indicator, Fv/Fm, was measured daily and the steady-state data is presented in Figure $2 \mathrm{~B}$. The figure demonstrated that microalgae growth was not inhibited even though the wastewater was untreated and non-sterilized. Infact, the Fv/Fm ratio or the maximum quantum yield of photosynthesis is a measure of the maximal photochemical efficiency of photosystem II of a darkness pre-adapted culture (Genty et al. 1989). This ratio is often used to measure the degree of photoinhibition (Figueroa at al., 1996, Casper-Lindley and Björkman, 1998) since it can be decreased by non photochemical quenching, a photoprotection mechanism, and by photodamage. It is worth noting that microscopic observations revealed the presence of pennate diatoms and green filaments in all the assays as well as bacteria and rotifers, yet the strain with which the experiment was inoculated was obviously the dominant one. This, however, suggests that for efficient wastewater utilization in microalgae production, further studies should be carried out to investigate the coexistence of microalgae and bacteria (Boelee et al., 
2014). In this study, the wastewater used was untreated and non-sterilized yet it perfectly supported the microalgae growth requirements, which implies that it could be used directly for microalgae cultivation without any pretreatment such as sterilization to remove rotifers and bacteria that could have an inhibitory effect on microalgae growth (Osundeko et al., 2013). Moreover, many studies have claimed that the application of sterilized conditions for microalgal biofuel production is energy-consuming and costly, which consequently makes the process inefficient and unsustainable. Results reported here prove that algal biomass can be produced sucesfully, with high biomass productivity using raw untreated wastewater, suggesting the potential for mitigating microalgal fuel production costs.

One of the microalgae growth requirements is the availability of primary nutrients such as carbon, nitrogen and phosphorus. Microalgae growth has been successfully sustained by using wastewater as the culture medium. Analyses of each strains' nurient removal

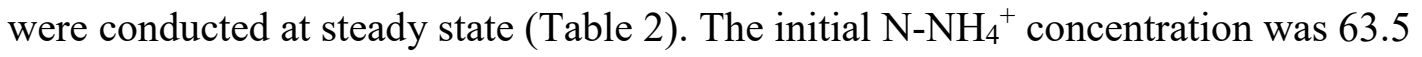
$\mathrm{mg} / \mathrm{L}$ and this significantly decreased to $0.2 \mathrm{mg} / \mathrm{L}$, when using strain WT10; whereas with strains WT6, WT8 and WT9, it went down to $0.3 \mathrm{mg} / \mathrm{L}$. As for $\mathrm{N}^{-\mathrm{NO}_{3}}{ }^{-}$reduction, the initial concentration decreased from $2.8 \mathrm{mg} / \mathrm{L}$ to $2.4 \mathrm{mg} / \mathrm{L}$ when using strain WT6, $2.6 \mathrm{mg} / \mathrm{L}$ using strain WT9, and $1.8 \mathrm{mg} / \mathrm{L}$ using strain WT8, with no nitrification being observed. However, the nitrification phenomenon was observed when using strain WT10, where the final $\mathrm{N}^{-\mathrm{NO}_{3}}{ }^{-}$concentration reached $5 \mathrm{mg} / \mathrm{L}$. This phenomenon is due to the transformation of ammonium ions to nitrite and nitrate ions by Nitrosomonas and Nitrobacter bacteria present in the wastewater (Mook et al., 2012). The initial $\mathrm{P}_{-} \mathrm{PO}_{4}{ }^{3-}$ concentration was $6.5 \mathrm{mg} / \mathrm{L}$, which decreased to $0.6 \mathrm{mg} / \mathrm{L}$ when using strain WT6 and WT8, to $0.4 \mathrm{mg} / \mathrm{L}$ using strain WT9, and to $0.2 \mathrm{mg} / \mathrm{L}$ using strain WT10. The main phosphorus-removing mechanisms are either assimilation by microalgae or precipitation 
due to elevated $\mathrm{pH}$ and high dissolved oxygen concentration (Cho et al., 2013, Ji et al., 2014). Because the $\mathrm{pH}$ was controlled at 8.0 and dissolved oxygen remained constant at $100 \%$ Sat., chemical precipitation was unlikely and phosphorus removal in this study presumed to be due to microalgae assimilation. The removal rates of nitrogen were in the 18.3-19.2 $\mathrm{mg} \mathrm{N} / \mathrm{L}$. day range (table 2). Similarly, phosphorus removal rates were in the 1.7-1.88 $\mathrm{mg} \mathrm{P} / \mathrm{L}$.day range. Regarding COD, the results showed significant differences between the removal capacities of each strain. In fact, the initial COD concentration in the wastewater was $1,120 \mathrm{mg} / \mathrm{L}$ and this decreased to $480 \mathrm{mg} / \mathrm{L}$ when using strain WT9, to $401 \mathrm{mg} / \mathrm{L}$ using strain WT10, to $124 \mathrm{mg} / \mathrm{L}$ using strain WT8, while it dropped dramatically to $92 \mathrm{mg} / \mathrm{L}$ when using strain WT6, achieving a maximum removal capacity of $91.8 \%$. In the light of the results obtained, the WT6 microalgae strain seems the appropriate choice to ensure both microalgae production and efficient nutrient removal.

\subsection{Potential of the selected Scenedesmus sp. microalgae strain for wastewater treatment and biomass production}

The selected microalgae strain, WT6, was identified as Scenedesmus sp. as mentioned in Materials and Methods section (2.2) and was the focus of the next experiments. To study the strain's performance, different dilution rates were applied to determine which was optimal in simultaneously ensuring maximum microalgae production and nutrient removal. In fact, continuous systems ensure tighter control and maximal biomass productivity by operating at the optimal combination of growth rate and biomass concentration. Furthermore, performing at a high dilution rate contributes to minimizing the contamination and the development of microalgae-grazing microorganisms. Similarly, all the nutrient removal efficiency analyses were performed at steady state. 
Figure $3 \mathrm{~A}$ and $3 \mathrm{~B}$ depict the variation of biomass productivity and chlorophyll fluorescence $(\mathrm{Fv} / \mathrm{Fm})$, respectively, with the dilution rates for the selected strain. As expected for light-limited cultures, the biomass concentration decreases when the dilution rate increases. The maximum biomass productivity achieved was $0.92 \mathrm{~g} / \mathrm{L} \cdot$ day at a dilution rate of 0.61 /day. This value of productivity obtained, which is higher than the $0.77 \mathrm{~g} / \mathrm{L} \cdot$ day after batch cultivation of Parachlorella hussii in non-autoclaved raw municipal wastewater secondary effluent (Osundeko et al,. 2013), the $0.27 \mathrm{~g} / \mathrm{L}$.day using sterilized secondary wastewater in a $2 \mathrm{~L}$ chemostat in continuous mode of Scenedesmus sp AMDD at 0.75 1/day (McGinn et al., 2012), and comparable to the productivity ( $0.92 \mathrm{~g} / \mathrm{L}$.day) obtained after continuous growth of Chlorella $\mathrm{sp}$. at a $50 \%$ daily harvesting rate in $25 \mathrm{~L}$ coil using raw centrate as the culture medium ( $\mathrm{Li}$ et al., 2011); whereas Gómez et al. (2013) obtained a productivity of 0.5 g/L.day from Muriellopsis sp. using secondary treated wastewater as the culture medium at a dilution rate of $0.31 /$ day.

Table 3 displays the nitrogen removal as $\mathrm{NO}_{3}{ }^{-}$and $\mathrm{NH}_{4}{ }^{+}$, in comparison with the initial wastewater nitrogen inlet content. Regarding nitrogen removal as $\mathrm{NO}_{3}{ }^{-}$, starting from an initial concentration of $2.3-2.8 \mathrm{mg} / \mathrm{L}$, an increase in concentration was observed at the dilution rates of 0.4 1/day, implying the occurrence of the nitrification phenomenon. The highest $\mathrm{N}_{-} \mathrm{NO}_{3}{ }^{-}$removal (44\%) was observed at 0.6 1/day. The initial N-NH${ }_{4}{ }^{+}$ concentration was $61.7-63.5 \mathrm{mg} / \mathrm{L}$ and this decreased for all the dilution rates applied achieving a maximum $\mathrm{N}-\mathrm{NH}_{4}{ }^{+}$removal of $99.4 \%$ at 0.31 /day and $99.1 \%$ at 0.2 and 0.4 1/day; whereas the experiment conducted at 0.81 /day exhibited the lowest nitrogen removal (a final concentration of $24.1 \mathrm{mg} / \mathrm{L}$ ) (Table 3). Many studies reported that ammonium is the preferred form of nitrogen for the microalgae because its assimilation process doesn't require the redox reaction, which means a lower energy requirement 
(Cai et al., 2013). Additionally, ammonium removal could take place through ammonia stripping. However, in the present study, the daily $\mathrm{pH}$ measurement does not record any $\mathrm{pH}$ increase above 9 since it was controlled by $\mathrm{CO}_{2}$ injection and the temperature was fixed, thus this phenomenon did not, most unlikely, take place during the experiment and the removal was would be mainly performed biologically (Cai et al., 2013, Rawat et al., 2011, Li et al., 2011).

We can conclude that nitrogen was efficiently and successfully removed during the various experiments. The final concentrations of $\mathrm{N}^{-\mathrm{NH}_{4}}{ }^{+}$for cultures at $0.2,0.3,0.4$ and 0.61 /day were $0.5,0.3,0.5$ and $0.6 \mathrm{mg} / \mathrm{L}$, respectively This is far more efficient than the $5 \mathrm{mg} / \mathrm{L}$ reported by Li et al. (2011) after 14 days of Chlorella sp. batch culture using raw centrate with an initial nitrogen concentration of $82.5 \mathrm{mg} / \mathrm{L}$. Table 3 presents the nitrogen removal rate and the nitrogen yield required for the species' growth per gram of biomass. The maximum removal rate was obtained at 0.61 /day corresponding to $34.6 \mathrm{mgN} / \mathrm{L}$.day. This removal rate is higher than the value obtained by McGinn and co-workers (2012), who obtained a removal rate of $8.85 \mathrm{mgN} / \mathrm{L}$.day using filtered and ultra-violet treated secondary effluent to cultivate Scenedesmus sp. AMDD in batch mode at $\mathrm{pH} 7$; and $24.4 \mathrm{mgN} / \mathrm{L}$.day in continuous mode at $0.751 /$ day. As for phosphorus (another important element required for cell growth and metabolism), Table 3 depicts its removal at different dilution rates. The initial $\mathrm{P}-\mathrm{PO}_{4}{ }^{3-}$ concentration was $6.5-21.9 \mathrm{mg} / \mathrm{L}$ in the wastewater used. At steady state, almost total P$\mathrm{PO}_{4}{ }^{3-}$ uptake was noted for all the dilution rates except that at $0.81 /$ day. This result is similar to the $\mathrm{N}-\mathrm{NH}_{4}{ }^{+}$removal at the same dilution rate and it is due to the very low culture retention time, at $0.81 /$ day, which is not sufficient for the species to remove the nutrient. Similarly, many authors obtained total phosphorus removal, such as Aravantinou et al. (2013) who conducted batch cultivations for different freshwater 
microalgae using synthetic wastewater at $30.5 \mathrm{mg} / \mathrm{L} \mathrm{P}_{-} \mathrm{PO}_{4}{ }^{3-}$ initial concentration. Table 3 presents the $\mathrm{P}-\mathrm{PO}_{4}{ }^{3-}$ removal rate and the phosphorus yield required for species' growth per gram of biomass at the different dilution rates applied. The highest $\mathrm{P}_{-} \mathrm{PO}_{4}{ }^{3-}$ removal rate was $16.2 \mathrm{mg}$ P/L.day achieved at 0.8 1/day whereas at $0.61 /$ day, it was 12.7 mgP/L.day. These values are higher than for McGinn and co-workers (2012), who obtained a removal rate of $0.91 \mathrm{mg} \mathrm{P} / \mathrm{L}$.day using filtered and ultra-violet treated secondary effluent to cultivate Scenedesmus sp. AMDD in batch mode at pH 7 and 2.8 mgP/L.day in continuous mode at 0.75 1/day. According to European Union Directive 98/15/CE, in relation to $\mathrm{N}$ and $\mathrm{P}$ requirements, the effluents from urban wastewater treatment permit $10 \mathrm{mg} / \mathrm{L}$ total nitrogen and $1 \mathrm{mg} / \mathrm{L} \mathrm{P}_{-} \mathrm{PO}_{4}{ }^{3-}$. The results obtained help to justify the use of this microalgae strain in meeting optimum nutrient removal requirements.

As far as the COD is concerned, Table 3 shows COD uptake by Scenedesmus sp. at different dilution rates. The initial COD concentration in the wastewater was 1,1201,180 mg/L. At the different dilution rates, all the cultures exhibited high COD removal, above $90 \%$. The highest removal, $93.7 \%$, was reached at a 0.61 day dilution rate - the final COD concentration being $73.9 \mathrm{mg} / \mathrm{L}$. This high removal could also be related to the high productivity achieved at this dilution rate. Indeed, this would be explained by the fact that, at 0.6 1/day, more microalgae grew, which meant more photosynthesis occurred generating more oxygen. Therefore, the oxidation of organic matter is enhanced by the presence of oxygen. The removal efficiency obtained is higher than that obtained by De Alva et al. (2013), who found a value of $77 \%$ after an initial COD concentration of $782.8 \mathrm{mg} / \mathrm{L}$ using pre-treated municipal wastewater to grow Scenedesmus acutus in batch mode. It is worth noting that the high COD concentration in the culture medium did not affect microalgae growth, which illustrates that 
Scenedesmus. sp is tolerant to high COD concentrations. Indeed, the maximum productivity was $0.9 \mathrm{~g} / \mathrm{L}$.day at $0.6 \mathrm{1} /$ day and the minimum was $0.5 \mathrm{~g} / \mathrm{L}$.day at 0.2 1/day. Additionally, this microalgae strain is able to take advantage of different carbon sources besides $\mathrm{CO}_{2}$. In fact, Park at al. (2011) claimed that the high COD removal indicates heterotrophic nutritional growth. Additionally, it should be mentioned that although Scenedesmus sp. was the dominant microorganism in the culture, it is obvious that heterotrophic bacteria had gradually developed and contributed to organic matter degradation. In the light of these results, it is clear that nutrient removal using microalgae compares well to classic wastewater treatment methods. According to the present study, the appropriate dilution rate to apply to Scenedesmus sp. for simultaneous biomass production and nutrient removal is $0.61 /$ day.

\subsection{Biochemical composition of the produced biomass}

At steady state, the biochemical composition of the biomass was evaluated and the results are presented in Figure 4. Results revealed that, at all the dilution rates applied, carbohydrates were the dominant biomass fraction. Carbohydrate content was in the 39.3-56.3\% (DW) range and this decreased as the dilution rate increased. Likewise, Samori at al. (2013) obtained high amounts of polysaccharides from the cultivation of Desmodesmus communis and a natural consortium of microalgae in batch mode under different growth conditions using wastewater or synthesized culture medium. Protein content ranged between 11.1 and $19.1 \%$ (DW). This relatively low protein content is favorable to microalgal biofuel production since the high protein content means a high proportion of nitrogen in the bio-oil produced. However, because of their undesirable effect on the environment, this mandates the need to remove the $\mathrm{NO}_{\mathrm{x}}$ compounds formed after burning the oil; or alternatively, upgrading the bio-oil by denitrogenation 
(Biller and Ross, 2011) - making the process more costly. Regarding the lipid content, the values obtained for the cultures at $0.2,0.3,0.4,0.6$ and 0.81 /day were 19.0, 15.1, $14.7,14.8$ and $13.0 \%$ (DW), respectively. No significant difference in lipid content was observed for the different dilution rates but a slight decrease in total lipids was observed as the dilution rate increased.

In previously published studies, a lipid content of $28.3 \%$ was obtained after Scenedesmus acutus cultivation in batch mode using pretreated municipal wastewater as the culture medium for 21 days (De Alva et al., 2013); while Abou-Shanab et al. (2013) reported a $31 \%$ lipid content after 20 days of batch-mode cultivation of Scenedesmus obliquus in sterilized piggery wastewater. These results are higher than those obtained in the present study. However, those works were conducted in batch mode where the medium became nutrient-depleted favoring stress condition and thus increased lipid content. Numerous studies have demonstrated that microalgae are able to accumulate high lipid content under stressful conditions (Xin et al., 2010). Interestingly, in the present study, growth and productivity were not affected even with the high ammonium and COD concentrations in the culture medium, suggesting that the wastewater used was not stressful enough to induce lipid accumulation. Similar lipid contents to those in the present study were obtained by Aravantinou et al. (2013), who performed Scenedesmus rubescens cultivation in batch mode using synthetic sterilized wastewater - obtaining $14.91 \%$ and $4.97 \%$ lipid content after 20 and 30 days, respectively; whereas, Arbib et al. (2014) obtained 19.38 and $18.5 \%$ lipid content after Scenedesmus obliquus cultivation using treated urban wastewater and synthetic wastewater, respectively, in batch mode under air bubbling enriched with $5 \% \mathrm{CO}_{2}$.

The data for the fatty acid profile analysis of the lipid fraction at the different dilution rates are summarized in Table 4 . Fatty acid content ranged from $4.6 \%$ to $13.2 \%$ (DW) 
and decreased as the dilution rate increased. Results revealed that the most common fatty acids for the different dilution rates were short-chain fatty acids namely $\mathrm{C} 16: 0$, C18:1n9, C18:3n3, C 18:0 and C18:2n6. The saturated fatty acid C16:0 represented a significant proportion at all the dilution rates ranging from 27 to $29.5 \%$ of total fatty acid content. The fatty acid C18:1n9 comprised $32.4-10.1 \%$ of total fatty acids, decreasing as the dilution rate increased; whereas the fatty acid C18:3n 3 remained at the same level (around 12\%) for the first three dilution rates whilst it dropped to $6.8 \%$ at 0.8 1/day. The fatty acid C18:0 reached its maximum (11.56\% of total fatty acid) at 0.4 1/day and its minimum, $6.5 \%$, at 0.21 day; whereas the $\mathrm{C} 18: 2 \mathrm{n} 6$ content dropped from $5.6 \%$ at $0.21 /$ day to $3 \%$ at $0.81 /$ day. These classes of fatty acids were likewise obtained in several studies (Abou-Shanab et al., 2013, Li et al., 2011,) but in different proportions due to the varying wastewater composition and culture conditions. The saturated and monosaturated fatty acids which are preferred for biodiesel production accounted for 54 to $68 \%$ of total fatty acids for the different dilution rates. In fact, it has been widely reported that neutral lipids are required for biofuel production (Biller and Ross, 2011) to ensure good fuel quality. Besides, many studies concluded that microalgae cultivation should be focused on biomass productivity rather than lipid content for sustainable, viable biofuel production (Pittman et al., 2011). The cetane number $(\mathrm{CN})$ is an important parameter to evaluate the biodiesel quality and it proportionally increases as the saturation of FAME increases. The $\mathrm{CN}$ for the best dilution rate (0.6 1/day) was calculated according to the Bamgboye and Hansen (2009) correlation. The calculated value was $59 \pm 1.35$, which was within the $43.7-69.1$ range found by other authors (Giordano et al., 2014) and higher than the standard value for biodiesel proposed by the international reference standard UNI EN 14214:2008.

\section{Conclusions}


Of the four isolates, Scenedesmus sp. was the best for ensuring wastewater treatment and biomass production. At a dilution rate of $0.61 /$ day, a maximum productivity of 0.9 $\mathrm{g} / \mathrm{L}$.day, a COD reduction from $1,180 \mathrm{mg} / \mathrm{L}$ to $73.9 \mathrm{mg} / \mathrm{L}$, a nitrogen removal rate of $34.6 \mathrm{mg} \mathrm{N} / \mathrm{L}$.day and a phosphorus removal rate of $12.7 \mathrm{mg} \mathrm{PO}_{4}{ }^{3-} / \mathrm{L}$.day-were obtained. A lipid content of $14.8 \%$ was determined along with a fatty acids profile with $54 \%$ of total fatty acids composed of saturated and monosaturated fatty acids. As such, this microalga offers greats potential in treating wastewater and producing biomass suitable for biofuel production.

\section{Acknowledgements}

This work was supported by Campus de Excelencia Internacional Agroalimentario (ceiA3) within the joint framework of supervised theses between the University of Almeria, Spain and the University of Sfax, Tunisia; and the EDARSOL Project (CTQ2014-57293-C3). We would also like to thank Aqualia S.A. for providing water samples and the Estación Experimental Las Palmerillas of Fundación Cajamar for collaborating in this research.

\section{References}

1. Abou-Shanab, R. A.I., Ji, M.K., Kim, H.C., Paeng, K.J., Jeon, B.H., 2013. Microalgal species growing on piggery wastewater as a valuable candidate for nutrient removal and biodiesel production. Environ. Manage. 115, 257-264.

2. Acién, F.G., Fernández, J.M., Magán, J.J., Molina, E., 2012. Production cost of a real microalgae production plant and strategies to reduce it. Biotechnol. Adv. 30, 1344-1353. 
3. Acién, F.G., Fernández-Sevilla, J.M., Molina Grima, E., 2011. A process to obtain biofuel from microalgae: Feasibility Analysis. Fourth Congress of the International Society for Applied Phycology. Halifax. Canada. p. 41.

4. Aravantinou, A. F., Theodorakopoulos, M. A., Manariotis, I. D., 2013. Selection of microalgae for wastewater treatment and potential lipids production. Bioresour. Technol. 147, 130-134.

5. Arbib, Z., Ruiz, J., lvarez-Díaz, P., Garrido-Pérez, C., Perales, J. A., 2014. Capability of different microalgae species for phytoremediation processes: Wastewater tertiary treatment, $\mathrm{CO} 2$ bio-fixation and low cost biofuels production. Water Res. 49, $465-474$.

6. Bamgboye, A.I., Hansen, A.C., 2008. Prediction of cetane number of biodiesel fuel from the fatty acid methyl ester (FAME) composition. Int. Agrophys. 22, 21-29.

7. Biller, P., Ross, A.B., 2011. Potential yields and properties of oil from the hydrothermal liquefaction of microalgae with different biochemical content. Bioresour. Technol. 102, 215-225.

8. Boelee, N.C., Temmink, B.G., Janssen, M., Buisman, C.J.N., Wijffels, R.H., 2014. Balancing the organic load and light supply in symbioticmicroalgal-bacterial biofilm reactors treating synthetic municipal wastewater. Ecol. Eng. 64, 213-221.

9. Brennan, L., Owende, P., 2010. Biofuels from microalgae-A review of technologies for production, processing and extractions of biofuels and co-products. Renew. Sust. Energ. Rev. 14, 557-577.

10. Cai, T., Park, S.Y., Li, Y., 2013. Nutrient recovery from wastewater streams by microalgae: Status and prospects. Renew. Sust. Energ. Rev. 19, 360-369. 
11. Chen, G., Zhao, L., Qi, Y., 2015. Enhancing the productivity of microalgae cultivated in wastewater toward biofuel production: A critical review. Appl. Energ. 137, 282-291.

12. Chisti, Y., 2007. Biodiesel from microalgae. Biotechnol. Adv. 25, 294-306.

13. Cho, S., Lee, N., Park, S., Yu, J., Luong, T. T., Oh, Y.K., Lee, T., 2013. Microalgae cultivation for bioenergy production using wastewaters from a municipal WWTP as nutritional sources. Bioresour. Technol. 131, 515-520.

14. De Alva, M. S., Luna-Pabello, V. M., Cadena, E., Ortíz, E., 2013. Green microalga Scenedesmus acutus grown on municipal wastewater to couple nutrient removal with lipid accumulation for biodiesel production. Bioresour. Technol. 146, 744748.

15. European Commission Directive, 1998. 98/15/EC of 27 February. Official J. Eur. Commun.

16. Feng, Y., Li, C., Zhang, D., 2011. Lipid production of Chlorella vulgaris cultured in artificial wastewater medium. Bioresour. Technol. 102, 101-105.

17. Giordano, M., Palmucci, M., Norici, A., 2014. Taxonomy and growth conditions concur to determine the energetic suitability of algal fatty acid complements. J. Appl. Phycol. DOI 10.1007/s10811-014-0457-5.

18. Gómez, C., Escudero, R., Morales M. M., Figueroa, F. L., Fernández-Sevilla, J. M., Acién, F. G., 2013. Use of secondary-treated wastewater for the production of Muriellopsis sp. Appl. Microbiol. Biotechnol. 97, 2239-2249.

19. Hegewald, E., Hanagata, N., 2000. Phylogenetic studies on Scenedesmaceae (Chlorophyta). Algol. Stud. 100, 29-39. 
20. Herbert, D., Phipps, P.J., Strange, R.E., 1971. Chemical analysis of microbial cells, in: Norris, J.R. and Ribbons, D.W. (Eds.), Methods in Microbiology. Academic Press, London and New York, pp. 209-344.

21. Ichimura, T., Itoh, T., 1977. Preservation methods of microalgae (I), in: Nei, T. (Ed.), Preservation methods of microorganisms. University of Tokyo Press, Tokyo, pp. 355-373.

22. Ji, F., Liu, Y., Hao, R., Li, G., Zhou, Y., Dong, R., 2014. Biomass production and nutrients removal by a new microalgae strain Desmodesmus sp. in anaerobic digestion wastewater. Bioresour. Technol. 161, 200-207.

23. Kessler, E., Schaefer, M., Huemmer, C., Kloboucek, A., Huss, V.A.R., 1997. Physiological, biochemical, and molecular characters for the taxonomy of the subgenera of Scenedesmus (Chlorococcales, Chlorophyta). Bot. Acta. 110, 244250.

24. Kochert, G., 1978. Handbook of phycological methods: Culture methods and growth measurements. First ed. Cambridge University Press, London.

25. Lewis, L.A., Flechtner,V.R., 2004. Cryptic Species of Scenedesmus (Chlorophyta) from Desert Soil Communities of Western North America. J. Phycol. 40, 1127 1137.

26. McGinn, P. J., Dickinson, K. E., Park, K. C., Whitney, C. G., MacQuarrie, S. P., Black, F. J., Frigon, J.C., Guiot, S. R., O'Leary, S. J.B., 2012. Assessment of the bioenergy and bioremediation potentials of the microalga Scenedesmus sp. AMDD cultivated in municipal wastewater effluent in batch and continuous mode. Algal Research. 1, 155-165.

27. Miksch, K., Cema, G., Corvini, P. F. X., Felis, E., Sochacki, A., Surmacz-Gorska, J., Wiszniowski, J., Zabczynski, S., 2015. R\&D priorities in the field of 
sustainable remediation and purification of agro-industrial and municipal wastewater. New Biotechnol. 32, 128-132.

28. Mook, W.T., Chakrabarti, M.H., Aroua, M.K., Khan, G.M.A., Ali, B.S., Islam, M.S., Abu Hassan, M.A., 2012. Removal of total ammonia nitrogen (TAN), nitrate and total organic carbon (TOC) from aquaculture wastewater using electrochemical technology: A review. Desalination. 285, 1-13.

29. Osundeko, O., Davies, H., Pittman, J. K., 2013. Oxidative stress-tolerant microalgae strains are highly efficient for biofuel feedstock production on wastewater. Biomass Bioenergy. 56, 284-294.

30. Park, J.B.K., Craggs, R.J., Shilton, A.N., 2011. Wastewater treatment high rate algal ponds for biofuel production. Bioresour. Technol. 102, 35-42.

31. Pittman, J.K., Dean, A.P., Osundeko, O., 2011. The potential of sustainable algal biofuel production using wastewater resources. Bioresour. Technol. 102, 17-25.

32. Rawat, I., Ranjith Kumar, R., Mutanda, T., Bux, F., 2011. Dual role of microalgae: Phycoremediation of domestic wastewater and biomass production for sustainable biofuels production. Appl. Energ. 88, 3411-3424.

33. Rodríguez-Ruiz, J., Belarbi, E., Sánchez, J.L.G., Alonso, D.L., 1998. Rapid simultaneous lipid extraction and transesterification for fatty acid analyses. Biotechnol. Tech. 12, 689-691.

34. Xin, L., Hu, H.Y., Ke, G., Sun, Y.X., 2010. Effects of different nitrogen and phosphorus concentrations on the growth, nutrient uptake, and lipid accumulation of a freshwater microalga Scenedesmus sp. Bioresour. Technol. 101, 5494-5500. 


\section{Figure captions}

Figure 1: Microscopic observations of the isolates, A: Strain WT6, B: Strain WT8, C: Strain WT9, D: Strain WT10 (magnification 100X).

Figure 2: Variation in biomass productivity (A) and $\mathrm{Fv} / \mathrm{Fm}$ ratio (B) for the different strains at steady state. Data values are means $( \pm \mathrm{SE})$ of three replicate cultures.

Figure 3: Variation in biomass productivity (A) and Fv/Fm ratio (B) of Scenedesmus sp. cultures at steady state as a function of the dilution rate. Data values are means $( \pm \mathrm{SE})$ of three replicate cultures.

Figure 4: Biochemical characterization of the algal biomass at steady state for the different dilution rates applied. Data values are means $( \pm \mathrm{SE})$ of three replicate samples. 